\title{
THE NITRATE NITROGEN POLLUTION AND THE NITROGEN REMOVAL BY PADDY FIELD IN AGRICULTURAL AREA
}

\author{
KURODA Hisao*, KATO Tasuku* and NAKASONE Hideo* \\ *College of Agriculture, IBARAKI University, 3-21-1 Chunou Ami, Ibaraki, 300-0393, Japan \\ (E-mail:kuroda@mx.ibaraki.ac.jp, tkato@mx.ibaraki.ac.jp,nakasone@mx.ibaraki.ac.jp)
}

\begin{abstract}
In Japan, Nitrate nitrogen pollution of the ground water by overuse of fertilizer in the upland field had become a serious issue. In order to purify it, the nitrogen removal method using the Topographical chain system was examined. Spring water from upland field was installed to test fields and the experiment was conducted over a long period. The result showed no significant difference for the three kinds of vegetation. In the irrigation period, organic matter supplied by the generation of algae sustained the nitrogen removal. In order to explore the mechanism of the nitrogen removal, experiments were conducted by sampling soil in thin layers. In the rice plot, rice stubbles were put back into the soil did not show significant differences among the layers. In the non-vegetation test plot, the surface and the lower layer had large nitrogen removal. In the shield plot there are no differences in the two upper layers but the lower layers have large value because organic matter below $2 \mathrm{~cm}$ layer had not been used for denitrification. Therefore it is thought that denitrification in the paddy fields (wetlands) had happened at around the upper $2 \mathrm{~cm}$ layer of soil surface
\end{abstract}

\section{KEYWORDS}

Denitrification, Nitrate nitrogen, Soil layer, Topographical chain

\section{INTRODUCTION}

High concentration of the nitrate nitrogen causes severe problems such as the eutrophication of lake or groundwater contamination. Recently, this pollution is widespread in agricultural areas in Japan. In this area, overuse of chemical fertilizer or animal manure to the upland field had caused many nitrogen issues. Nitrate nitrogen concentration in six spring water from the upland field is investigated in (Kuroda 1998). The result showed a big difference where the spring water is close to each other. The distance between the two spring water is $14.1 \mathrm{~m}$ and the different in nitrate nitrogen concentration was from $0.3 \mathrm{mg} \cdot \mathrm{L}^{-1}$ to 60.7 $\mathrm{mg} \cdot \mathrm{L}^{-1}$. This showed that the flow of underground water is not uniform. Furthermore, large quantities of nitrogen from overuse of fertilizer stayed in the soil for a long time. As a result, the soil has an out flow of high concentration of nitrate nitrogen in a long term. However, in Japan, there are many paddy fields (and wetland) at the downstream region. Therefore we report the nitrogenous purification by paddy field.

\section{FIELD STUDY}

\section{Experiment Plots and method}

The flow diagram of an agricultural area is shown in Fig.1 (Tabuchi et al.). The land use the typical geological formation (known as "Yatsuda" in Japanese) in the Kanto Plain is shown in Fig. 2. This has 
fields and forests on a plateau and a wetland which includes a paddy field in the lowlands. Initial investigation showed that certain areas of the Lake Kasumigaura basin in Ibaraki pref. has nitrate nitrogen concentration of groundwater over $10 \mathrm{mg} / 1$. From Fig.1, although the upland is the type that discharges loads, it is understood that the amount of load decreases as it passes through the lowlands. A wetland has a natural purification function for nitrogen and is therefore considered important in the curtailment of nitrogen loads flow into the lake.

The experiment plots are shown in Fig.3. Data from the plots are collected from 1991 to 1998. A weed plot is one of the test plot in which weeds are allowed to grow freely from the first stage. A rice plot is a test plot which represents the rice crop. A non-vegetation plot is a test plot that had all vegetation removed by hands.

\section{Results}

The change in the amount of nitrogen removal in the vegetation period (from May to early September in Japan) is shown in Fig.4. Although the amount of removal was large at the early stage, it gradually slowed down and seemed to stabilize when it reached about 0.3

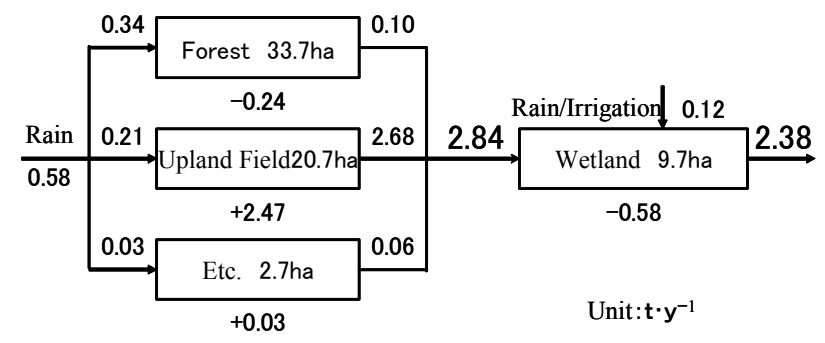

Fig.1 Flow diagram in the Agricultural Area

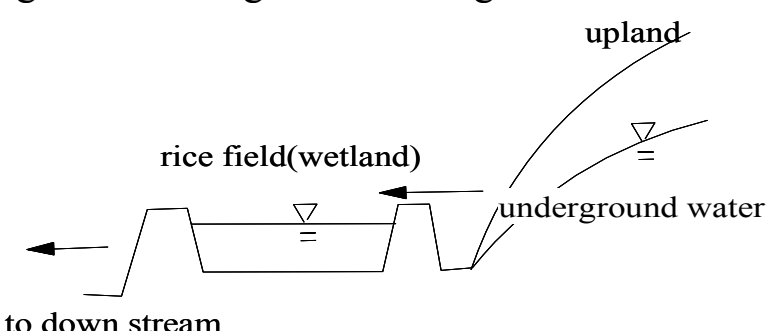

Fig.2 Outline of topographical chain

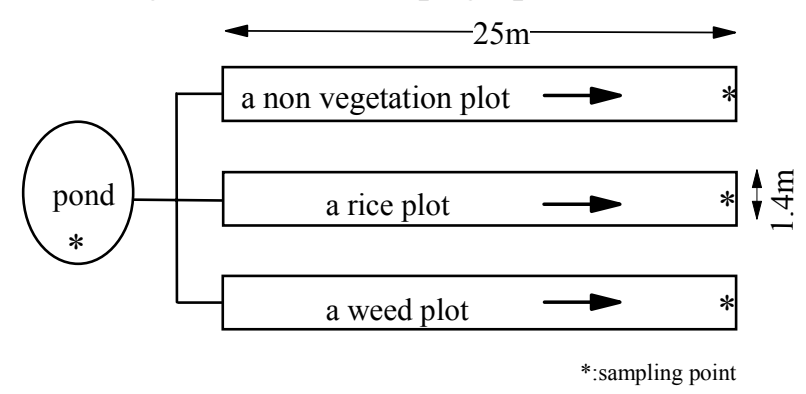

Fig.3 Outline of Experiment Plots

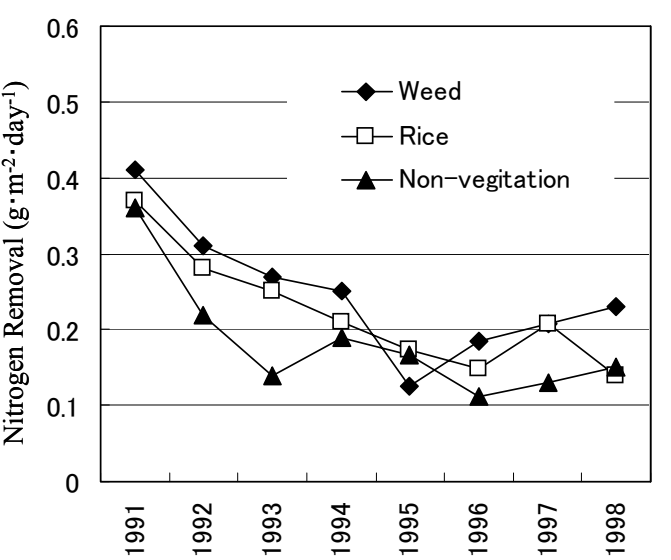

Fig. 5 The amount of Nitrogen removal Changes in a non vegetation period

$\mathrm{g} \cdot \mathrm{m}^{-2} \cdot$ day $^{-1}$. The amount of removal during the non vegetation period is shown in Fig.5. The amount of nitrogen removal continued to fall gradually. This is because the non vegetation period is under the influence of low temperature of winter. And algae generation is low during this period. Consequently there is little supply of organic matter. However, for both periods, the three types of vegetation did not show much difference in nitrogen removal.

\section{NITROGEN REMOVAL TEST}

Nitrogen removal function is based on vegetation absorption and a denitrification. In the non-vegetation plot removal is mostly performed by denitrification but there are also signs of algae growing there. The organic matter supplied by the withering death of these algae played a big role in the durability of nitrogen 
removal. At places where major denitrification phenomena had occurred, a bigger amount of nitrogen removal is expectable. Therefore, in order to investigate at which layer of the soil denitrification had occurred, we decided to examine the amount of removal by the layers. Since the weed test plot mentioned earlier has roots in every layer of the soil, it is considered not suitable for experiment. A new light shielded non-vegetation test plot ( we called this "shield plot" from here onwards) which has a sheet to cut off lights was installed to replace the weed test plot. Other paddy test plot and the non-vegetation test plot are used as it is.

\section{Methods}

To measure the amount of nitrogen removal by each soil layers, soil sample are layered thinly for every $\mathrm{cm}$. The layers are divided into a $0-1 \mathrm{~cm}$ layer(surface layer), a $1-2 \mathrm{~cm}$ layer, a $2-3 \mathrm{~cm}$ layer, a $5 \sim \mathrm{cm}$ layer. $100 \mathrm{~g}$ of soil sample from each layer is put into a $500 \mathrm{~cm}^{3}$ beaker each. $300 \mathrm{~cm}^{3}$ of $20 \mathrm{mg} \cdot \mathrm{L}^{-1}$ of nitrate nitrogen solution is put into the beaker and left to stable for one week in a dark room of 25 degree C. After a week, the solution is exchanged with a new solution. When the amount of nitrogen removal is almost lost, nitrate nitrogen solution is replaced with glucose so that it might become $\mathrm{C} / \mathrm{N}$ ratio 2.0.

\section{Results}

The experiment result of nitrate nitrogen concentration in the $0-1 \mathrm{~cm}$ layer is shown in Fig.6, 1-2 $\mathrm{cm}$ layer is shown in Fig.7, 2-3 cm layer in Fig.8 and 5- cm layer is shown in Fig.9. At 0-1 cm layer, nitrogen removal in the shield plot soil is smaller than others. The nitrogen removal capability of the shield plot is lost after week 3 . The nitrate nitrogen concentrations in the rice test plot soil and non-vegetation test plot soil showed almost the same tendency. As the weeks passed, the concentration decreased gradually. The removal capability is almost lost after week 10 . The removal capability is recovered when glucose $(\mathrm{C} / \mathrm{N}$ ratio 2.0) is added after week 13 . At the $1-2 \mathrm{~cm}$ layer, the removal capability except for rice field soil is lost after week 6. Reduction in the shield plot soil is larger than in the non-vegetation test plot soil. It recovered, when glucose is added. At the $2-3 \mathrm{~cm}$ layer the result is almost similar to the $1-2 \mathrm{~cm}$ layer. At 5- cm layer, all the 3 test plots soil showed the same tendency. The nitrogen removal capability is almost gone after ten weeks.

Since only the rice test plot soil had rice stubble of the previous year put into the soil during rice planting, it is considered that the organic matter from the rice stubble remained in the soil. On the other hand, it is thought that the organic matter in the soil from the two other test plots are used for denitrification. In the non-vegetation plot soil and shield plot soil, the difference in the amount of removal for the $0-1 \mathrm{~cm}$ layer is due to the different amount of organic matter on the surface soil. In the shield plot, the generating of algae is controlled by

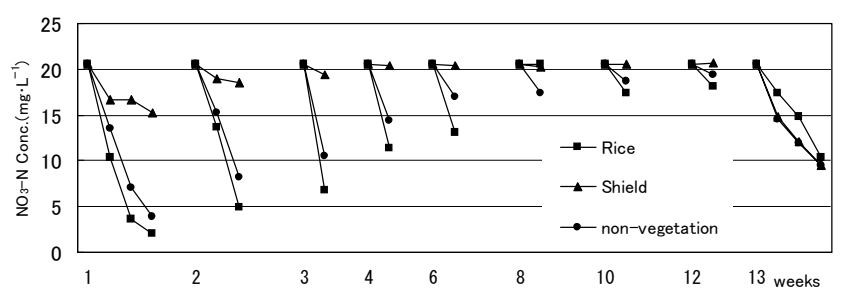

Fig. 6 The change of $\mathrm{NO}_{3}-\mathrm{N}$ Conc. at $0-1 \mathrm{~cm}$ layer

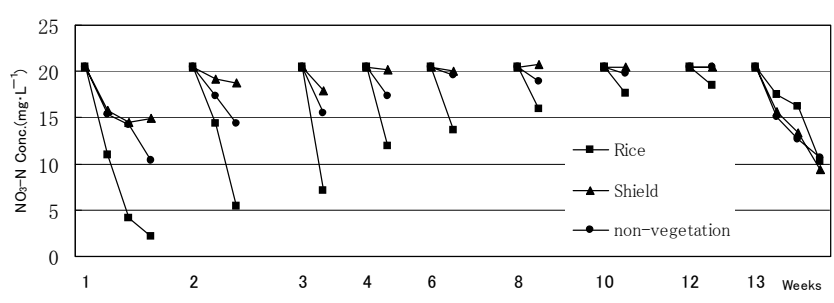

Fig. 7 The change of $\mathrm{NO}_{3}-\mathrm{N}$ Conc. at 1-2 cm layer

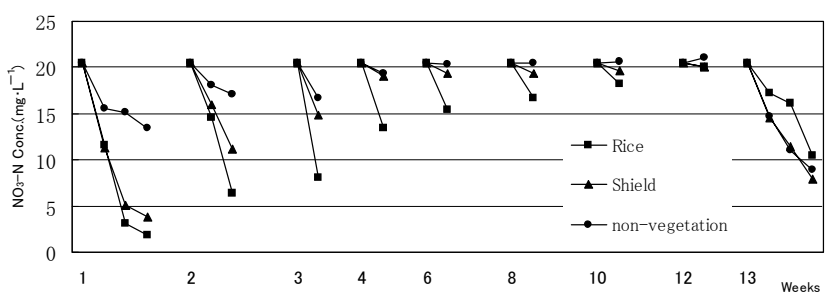

Fig.8 The change of $\mathrm{NO}_{3}-\mathrm{N}$ Conc. at 2-3 cm layer

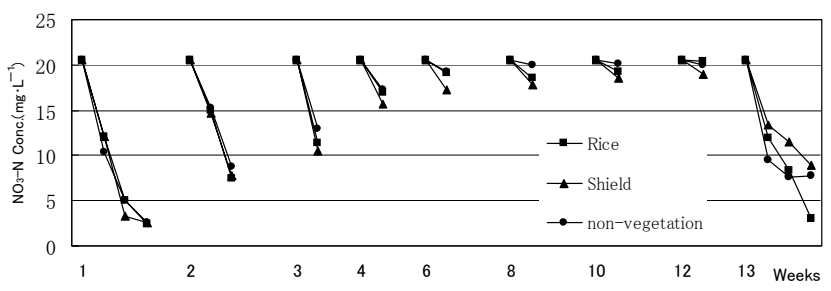

Fig.9 The change of $\mathrm{NO}_{3}-\mathrm{N}$ Conc. at 5- cm layer 
cutting off light with a sheet. This caused the amount of organic matters to decrease. Since at the 2-3 cm layer, both the rice and non-vegetation field soil showed the same result, it is thought that the organic matter in the 2-3 cm layer are seldom used for denitrification. These results showed that soil layer thickness required for denitrification is below $2 \mathrm{~cm}$.

The result is then compared with the coefficient of nitrogen removal. A nitrogen removal formula (Tabuchi T. 1998) is shown below.

$$
D=F \cdot P \cdot R_{0}
$$

$D\left(\mathrm{~g} \cdot \mathrm{m}^{-2} \cdot\right.$ day $\left.^{-1}\right):$ the amount of nitrogen removal on paddy field, $F$ : the coefficient of vegetation (1-4), $P$ : the coefficient of water flow $(0-1), R d\left(\mathrm{~g}^{-} \mathrm{m}^{-2} \cdot\right.$ day $\left.^{-1}\right):$ the amount of nitrate nitrogen by denitrification

$$
R_{0}=q X_{0}\{1-\exp [-a / q]\}
$$

$q=Q / A: Q$ is inlet flow per day $\left(\mathrm{m}^{3} /\right.$ day $), A:$ paddy field area $\left(\mathrm{m}^{2}\right), X_{0}$ : nitrate nitrogen concentration $\left(\mathrm{mg} \cdot \mathrm{L}^{-1}\right)$,

$a$ : the coefficient of nitrogen removal

$$
a_{0}=0.000011 T^{2}+0.005
$$

Results are shown in Figs.10-12. Although the value decreases in the early stage, as the week passed the coefficient of nitrogen removal in the rice plot did not show significant difference between the layers,

The upper two layers in the shield plot soil did not show any difference but soil from layers below $2 \mathrm{~cm}$ have large value. In the non-vegetation plot soil, 0-1 cm layer and 5- cm layer have large value. Other layers' values are small.

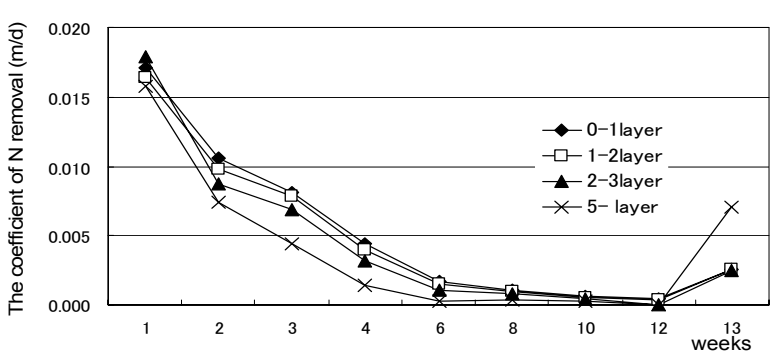

Fig.10 The coefficient of Nitrogen removal changes at a rice plot soil

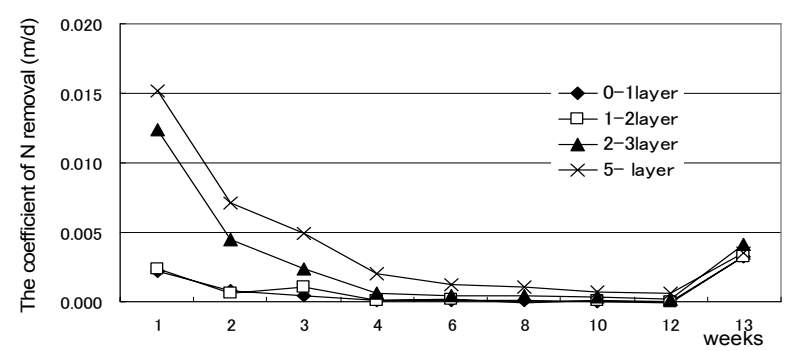

Fig. 11 The coefficient of Nitrogen removal changes at a shield plot soil

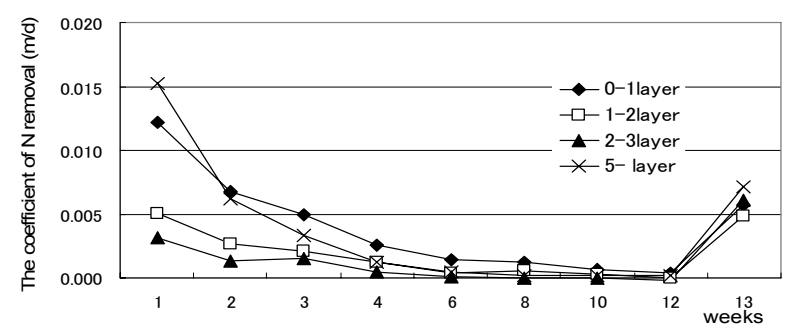

Fig. 12 The coefficient of Nitrogen removal changes at a non-vegetation plot soil

\section{CONCLUSION}

This experiment showed the following. There is no significant difference in the result of the three kinds of vegetation. During the vegetation period, it appeared that organic matter is supplied by the generation of algae and nitrogen removal is thus sustainable.

In order to explore the mechanism of nitrogen removal, experiments were conducted by sampling soil in thin layers. In the paddy rice division where rice stubbles were put into soil, neither layers show any differences. In the non-vegetation plot soil, the surface and the lower layer had large nitrogen removal. In the shield plot soil, the lower layers have large value. This is due to the fact that organic matter below $2 \mathrm{~cm}$ layer is not used for denitrification. From these results, it is thought that denitrification of paddy fields (wetlands) has happened at about $2 \mathrm{~cm}$ of the soil surface layer.

\section{References}

Kuroda H., (1998), A Method of Water Quality Management on Topographical Chain. Jour. JSIDRE 66 (12), 1223-1227. (in Japanese)

Tabuchi T., Kuroda H., (1991), Nitrogen Outflow Diagram in a Small Agricultural Area Having Uplands and Lowlands. Trans. JSIDRE 154,65-72. (in Japanese)

Tabuchi T., (1998), Nitrogen Outflow Model with Nitrogen Removal Function by Paddy Fields, Journal of the Japanese Society of Soil Physics78, 11-18 (in Japanese) 